\title{
Islam político. Enfoques y problemas conceptuales para una mejor comprensión
}

\section{Political Islam. Conceptual approaches and issues for a better understanding}

ARTÍCULO DE REVISIÓN

\author{
Enrique Herszkowich \\ Universidad de Buenos Aires, Argentina. \\ emherszkowich@gmail.com
}

Recibido: junio del 2016

Aceptado: agosto del 2016

\section{Resumen}

Desde el último cuarto del siglo XX hizo irrupción en Medio Oriente primero, y en Occidente después, una nueva forma de participación política que legitimaba sus acciones y recusaba la de sus adversarios con el lenguaje del islam. Esta movilización, identificada aún en algunos círculos como formas de fundamentalismo o integrismo, o expresiones de fanatismo e irracionalidad, generó múltiples interpretaciones y explicaciones. En la actualidad, siguen surgiendo nuevas expresiones de este fenómeno, siendo el más reciente el conocido como Estado Islámico, que se relaciona no sólo con los conflictos geopolíticos del Medio Oriente, sino también con las contradicciones propias de las sociedades occidentales, sobre todo en Europa y los Estados Unidos. El presente artículo aborda las diferentes formas de concebir, explicar e interpretar al islam político, junto a sus implicancias conceptuales, epistemológicas y políticas. Es parte de una tesis más amplia que analiza particularmente la mirada del PTS sobre este fenómeno.

Palabras clave: islamismo; islam; fundamentalismo; integrismo.

\begin{abstract}
Since the last quarter of the twentieth century a new form of political participation that legitimized their actions and refuted their opponents with the language of Islam has made irruption in the Middle East first, and in the West after. This mobilization, still identified in some circles as forms of fundamentalism or intégrisme, or expressions of bigotry and irrationality, generated multiple interpretations and explanations. Today, new expressions of this phenomenon, the most recently known as the islamic State, which are related not only to the
\end{abstract}


geopolitical conflicts in the Middle East, but also with the contradictions of Western societies, especially in Europe and the United States, are still emerging.

This article discusses the different ways of conceiving explaining and interpreting Political Islam, with its conceptual, epistemological and political implications. It is part of a broader thesis which particularly analyzes the PTS's (Socialist Workers Party) point of view on this phenomenon.

Keywords: Islamism; Islam; fundamentalism; intégrisme. 
En los últimos treinta años se ha desarrollado, primero en Medio Oriente, y luego en algunas comunidades musulmanas de Occidente, una nueva forma de movilización política basada en el discurso del islam, conocida, entre otras formas, como islam político o islamismo. Tal movilización, que puede ser tanto conservadora como altamente contestataria, ha generado múltiples debates que intentaron problematizar e interpretar el fenómeno.

Algunas interpretaciones enfatizaron los factores culturales o religiosos (Laroui, 1991; Löwy, 1996; Ramadán, 2000; Burgat, 1996; Abu Amr, 1996; Sivan, 1997), mientras que otras intentaron explicar al islamismo como una manifestación de la lucha de clases (Kepel, 2001; Étienne, 1996; Jhosrokhavar-Roy, 2000; Rodinson, 1996; Ayubi, 1996). También fue relacionado este fenómeno con un contexto político caracterizado por la falta de libertades civiles y de derechos (Martín Muñoz, 1999; Izquierdo Brichs, 2011; Serfaty, 1996).

Desde la penetración colonial en el mundo árabe - islámico, a finales del siglo XIX y comienzos del $\mathrm{XX}$, las guerras independentistas y la consolidación de los regímenes poscoloniales, y hasta el proceso conocido como Primavera Árabe (Gutiérrez de Terán y Álvarez Ossorio, 2012; Izquierdo Brichs, 2013; Álvarez Ossorio, 2013; Mesa Delmonte, 2012), a comienzos del año 2011, el islam político adquirió múltiples expresiones, reivindicaciones y formas de lucha.

De esta manera, el fenómeno en cuestión ha representado no sólo un desafío para los regímenes establecidos en el mundo árabe - islámico, sino también para los analistas occidentales. Entre estos analistas, algunos han visto en los movimientos islámicos la expresión política de una identidad cultural tradicionalista y antimodernista, mientras que otros lo han idealizado como una manifestación cultural contrahegemónica (Ternisien, 2007). La clase, la cultura, la política, entre otros tópicos, han servido para elaborar diferentes interpretaciones del fenómeno.

\section{Interpretaciones y política local. Entre el norte y el sur}

En Europa Occidental y en los Estados Unidos los debates en torno a los significados del islam político reflejaban problemáticas vinculadas a diversos escenarios específicos de esas sociedades. Algunas de estas problemáticas eran la legitimación o la impugnación de las políticas exteriores de sus respectivos gobiernos; la reelaboración (crítica, legitimadora, o reparadora) de sus propias historias como potencias colonizadoras (tanto en el pasado, como en el caso de Francia en Argelia, o Gran Bretaña en Egipto, como respecto de sus intervenciones directas en el presente, como en el caso de Estados Unidos en Afganistán o Iraq) o la elaboración de discursos de inclusión/exclusión de la cultura islámica en general y de los musulmanes en particular, en el marco de las reivindicaciones ciudadanas 
de cada una de las sociedades en cuestión, en un contexto de diversos grados de racismo, xenofobia o nacionalismo antimusulmán y de crisis del multiculturalismo (Goody, 2005; AlSayyad y Castells, 2003; Jameson y Zizek, 2003; Ramadán, 2002; Roy, 2003 y 2006; Sartori, 2001).

En cambio, en América Latina y en particular, en Argentina, el interés y las preguntas acerca del islam político fueron, necesariamente, diferentes. En primer lugar, porque no hay un pasado de intervención colonial como potencias colonizadoras; en segundo lugar porque, por su grado de influencia, los gobiernos no estuvieron tan directamente involucrados en la agenda de la resolución de los conflictos internacionales; y en tercer lugar, porque, al menos en Argentina, no existió todavía una militancia islamista, es decir, comunidades musulmanas que expresaran sus posiciones políticas o se movilizaran políticamente -es decir, públicamente- ya sea como ciudadanos o con reivindicaciones de carácter local o universales, mediante un discurso islámico.

Sin embargo, también en Argentina hubo diferentes momentos en que pareció surgir una cuestión islámica. El primero de esos momentos, tuvo que ver con las repercusiones que sobre la comunidad musulmana local tuvieron los atentados, en la ciudad de Buenos Aires, contra la Embajada del Estado de Israel (1992) y contra la Asociación Mutual Israelita Argentina (1994). Entre esas repercusiones, la comunidad islámica, después de un período de "ocultamiento y discreción" (Vagni, 2011) debió aparecer públicamente asumiendo posiciones, e incluso explicando en qué consiste la identidad islámica en general y la de los musulmanes argentinos en particular, y, sobre todo, tomando distancia de sus identificaciones con el terrorismo (Brieger - Herszkowich, 2003). Es de destacar, entonces, que esta mayor visibilidad de la comunidad islámica en Argentina se produjo en la mencionada década de 1990, y no después de los atentados del 11 de septiembre de 2001 en Estados Unidos, como sucedió en otros lugares del mundo (Montenegro, 2010).

En la década siguiente, sendos conflictos armados ocurridos en Medio Oriente, por un lado la invasión de Israel al Líbano (2006) y por otro lado, los bombardeos israelíes a la Franja de Gaza (2009), generaron nuevamente la exposición pública de la comunidad musulmana argentina, esta vez expresando su solidaridad con los árabes libaneses y palestinos, y su repudio al Estado de Israel.

\section{Islam político. Problemas de definición}

En la bibliografía que analiza al islam político se pueden distinguir tres ejes que concentran la atención de los autores y orientan su interpretación del fenómeno. El primero es la discusión en torno a la denominación correcta para el objeto descripto; en segundo lugar, se encuentran los debates acerca de cuáles son las variables que se deberían enfatizar para explicar el éxito de este discurso, entre las cuales sobresalen las que hacen 
hincapié en las expresiones de clase, en las demandas políticas, y en las reivindicaciones culturales; por último, aparecen las discusiones acerca de la relación entre las élites dirigentes de los movimientos islámicos y sus bases sociales de apoyo. En este trabajo se desarrollan en profundidad las discusiones planteadas en los dos primeros ejes que retoman los problemas en torno a la denominación y los enfoques de abordaje.

Con respecto a la primera cuestión, algunos autores aún utilizan las denominaciones más etnocéntricas, es decir, las originadas en el marco del cristianismo occidental de los dos últimos siglos. Por ejemplo y a pesar de sus connotaciones negativas, se utilizan las nociones de fundamentalismo (Abu Amr, 1994; Armstrong, 2004) e integrismo (Garaudy, 1992; Elorza, 2004). La primera de ellas suele aún estar asociada a las producciones del mundo anglosajón, mientras que en los países de tradición latina, se utiliza más frecuentemente la segunda (Brieger, 1996). Otros autores, enfatizando que no se deben privilegiar los componentes religiosos del fenómeno sino los políticos (Abu Amr, 1996), utilizan en cambio nombres exclusivos que no connotan las especificidades cristianas. Así, se sostiene la conveniencia de las denominaciones islam (o islamismo) radical (Carré, 1985; Étienne, 1996; Sivan, 1997) o radicalismo islámico (Pierucci, 1992), islamismo (Roy, 1996; Burgat, 1996 y 2006; Martín Muñoz, 1999; Kepel, 2001; Rashid, 2002; Arístegui, 2004; Mires, 2005; Veiga, 2011), movimientos islámicos (Brieger, 1996), islam político (Ayubi, 1996; Brieger, 1996; Barreñeda, 2011; Izquierdo Brichs, 2011), o activismo islámico (Fadlalla, 1995). Estas designaciones también implican problemas metodológicos y conceptuales, como su vinculación con la violencia en algunos casos (Alonso Marcos, 2011; Lampridi-Kemou, 2011), o la confusión con el islam en tanto religión (Rodinson, 1996). La denominación escogida involucra la discusión en torno a la separación de las esferas política y religiosa en el islam (Étienne, 1996; Ayubi, 1996).

En cuanto al segundo eje propuesto, y a la búsqueda de las variables que explican el crecimiento del fenómeno en los últimos treinta años, se ha extendido en los medios de comunicación la idea que lo relaciona con el fanatismo religioso, vestigios de medievalismo, reacción bárbara, atavismos arcaicos (Herszkowich, 2006) o, incluso, con el fascismo (Ternisien, 2007) en visiones ajustadas a la idea del choque de civilizaciones (Huntington, 1993) y en algunos analistas especializados (Lewis, 2003). Estas perspectivas que vinculan al islam como religión con su mayor o menor apego, o incluso con el rechazo de ciertos valores de la modernidad occidental, tienden a fijar en el ámbito de las diferencias culturales, esenciales distinciones equiparables a lo que en otro momento se hubiese atribuido a las razas (Grimson - Semán, 2005). En otras palabras, la corrección política evita recurrir al concepto raza, eludiendo el vocablo, pero no las prácticas, "como si la abolición/reemplazo de ciertos términos en los usos sociales y académicos bastara por sí misma para suspender/morigerar los actos de inscripción de algunas desigualdades sociales" (Briones, 1998). 
En contraposición con estos abordajes, otros autores enfatizan el carácter construido de las identidades. Por ejemplo, es lo que se sugiere al afirmarse que en una sociedad preindustrial la cultura autóctona no es percibida, sino que la misma surge del choque con otras culturas, convirtiéndose entonces en identidad (Gellner, 1991). Por lo tanto, ninguna identidad es algo dado y pre-existente, sino que es un producto histórico, es decir, fruto de un período concreto, en la cual se gesta y difunde. Por otra parte, esa identidad, aun cuando pretenda afirmar una homogeneidad pre-existente, suele reflejar, por el contrario, la necesidad de crear dicha homogeneidad, por lo que parte de su no-existencia (Hobsbawm, 1992).

A partir de ese carácter construido, no esencialista, entonces, algunos autores (Ramadán, 2000; Al- Sayyad-Castells, 2003) pretenden también abordar al mundo musulmán a partir de las múltiples adaptaciones y expresiones que el islam puede tener, no sólo al coincidir con ciertos valores occidentales, sino incluso para desarrollarse en el mundo occidental. Estas visiones suelen partir de posiciones políticas cercanas al multiculturalismo. Sin embargo, el esfuerzo en declarar el rechazo a las miradas esencialistas -que niegan las identidades heredadas o biológicamente dadas- y su afirmación de que "todas las culturas están fragmentadas, resultan impugnadas internamente y presentan fronteras porosas", puede contradecirse con su defensa del valor de la diferencia respecto de una cultura hegemónica, en este caso, occidental, como si la diferencia fuera valiosa en sí misma (Piñeiro, 2004). De esta manera, se volvería a revestir a las identidades con una carga de esencialismo, en tanto, en sí mismas, serían una especie de discurso contrahegemónico. Por otra parte, mientras se rescata la cultura contrahegemónica como flexible, cambiante y fluida, se le suele atribuir a las culturas dominantes la misma uniformidad esencialista que se intenta combatir (Sorj, 2007, p. 40).

Sin embargo, este sobredimensionamiento de la variable cultural también puede realizarse desde perspectivas históricas, y no esencialistas. Es el caso tanto de las críticas al islamismo realizadas por Laroui (1991) o Löwy (1996), como de la defensa que hacen Ramadán (2000) o Martín Muñoz (1992), así como de los enfoques que enfatizan el problema de la identidad, como en el caso de Izquierdo Brichs (2011), Carré (1985), Sivan (1997) y, en muchos pasajes, Rodinson (1996) y Burgat (1996).

Otros autores, en cambio, enfatizan para explicar al islam político las reivindicaciones y las expresiones de los intereses de clase, sea para señalar la fortaleza de estos movimientos, como para indicar su debilidad (Kepel, 2001; Étienne, 1996; JosrokhavarRoy, 2000; Rodinson, 1996).

El último grupo de autores destaca las reivindicaciones políticas, sobre todo en relación a las demandas de mayores libertades civiles y ciudadanas (Gannouchi, 1996; Martín Muñoz, 1999). En este eje aparece la discusión acerca de si el islamismo es compatible o no con la democracia occidental, desde autores que plantean la 
incompatibilidad más absoluta (Löwy, 1996) hasta aquellos que, desde miradas neotercermundistas, perciben identidad entre la democracia y el islam (Izquierdo Brichs, 2011). Al respecto, y desde un análisis más profundo, sobre todo de fuentes primarias y testimonios, otros especialistas sostienen que los manifiestos islamistas contra la democracia son en realidad contra la democracia occidental (Burgat, 1996).

El tercer eje mencionado es la discusión acerca de la relación entre los movilizados y los dirigentes en el contexto del islam político. Algunos autores cuestionan que los movimientos islámicos que se ubican al frente de las movilizaciones populares sean la vanguardia de las mismas (Izquierdo Brichs, 2011; Feliú, 2013), y otros afirman directamente que tales movimientos actúan a remolque de esas movilizaciones (Abu Amr, 1996; Lampridi-Kemou, 2011; Álvarez Ossorio-Ramírez, 2013). Finalmente, algunos autores encuentran una conexión entre la efectividad del discurso político y la relación entre élites y masas, lo cual los conduce nuevamente a cuestionar y revisar la noción de identidad (Serfaty, 1996).

\section{Integrismo y fundamentalismo, dos nombres cristianos}

Uno de los primeros problemas que presentó el fenómeno del islam político fue el de su denominación. Algunas de las designaciones más extendidas, sobre todo en la prensa, pero también en parte de la bibliografía especializada, remiten a dos fenómenos surgidos en el cristianismo contemporáneo occidental: fundamentalismo e integrismo. El primero de ellos suele estar asociado a las producciones del mundo anglosajón (Abu Amr, 1994; Armstrong, 2004), mientras que en los países de tradición latina (Garaudy, 1992; Elorza, 2004) suele utilizarse el segundo (Brieger, 1996). Sin embargo, ambos términos, además de sus cargas peyorativas, connotan fenómenos que no necesariamente representan al islam político.

El integrismo se trata de un término surgido en el seno de la Iglesia Católica Romana, a comienzos del siglo XX. El integrismo se utilizaba para denominar a aquellos grupos católicos que se oponían más fervientemente a las reformas destinadas a conciliar a la Iglesia con la sociedad burguesa y liberal propia de la Europa industrial. Los católicos integrales (o integristas) eran clericales, anti-republicanos y monárquicos, así como defensores de la soberanía temporal del papado y acérrimos críticos de la libertad de conciencia y de culto. Además, defendían la autoridad sacra de una pretendida interpretación literal de los textos papales (no de la Biblia), el celo militante de la defensa de los valores religiosos tradicionales (amenazados por la modernidad), la Iglesia jerárquica como modelo del único orden legítimo sociopolítico y, concomitantemente, la necesidad imperiosa de la recuperación del control político. Sus principales enemigos eran 
el liberalismo, la ciencia y la crítica histórica, y, sobre todo, el Estado Moderno, que había hecho de la religión un asunto privado (Pierucci, 1992).

Como se desprende de lo anterior, el integrismo implica también un ordenamiento socio-político que promueve una organización social en la cual la Iglesia se convierte en rectora y, siendo el modelo prerrevolucionario el ideal, puede ser asociado a una ideología reaccionaria.

Por su parte, el fundamentalismo tiene su origen en el protestantismo de Estados Unidos, cuando un grupo de pastores de diversas iglesias proclamaron la necesidad de luchar por ciertos principios fundamentales de la fe. Su principal pilar es el principio de la inspiración divina de la Biblia, su infalibilidad y la autoridad absoluta de su letra. Sus enemigos son la teología liberal, la crítica histórica y literaria, y la mentalidad científica moderna representada, sobre todo, por el darwinismo.

En efecto, la penetración de las narrativas evolucionistas en las escuelas significaba para los fundamentalistas- la más clara señal de la decadencia moderna. Para contrarrestarla, se proclamaba el retorno a la Biblia, que debía gobernar la nación, la familia, la escuela y, en suma, la vida cotidiana toda. En ese sentido, el proyecto fundamentalista se asemeja, en parte, a un proyecto integrista. Sin embargo, la política no se encuentra en primer lugar, sino que es primero la moral privada, y sólo luego la pública, la mayor preocupación.

Esas iglesias fundamentalistas reivindicaban una interpretación pretendidamente literal de la Biblia, sobre todo en lo referido a la Creación (Armstrong, 2004). Mientras los fundamentalistas deseaban volver a las fuentes o los fundamentos, a la letra revelada, los integristas reclamaban la defensa de la tradición, es decir, que a diferencia de los primeros para el integrista la lectura de los textos revelados no era directa, sino mediada por los expertos.

La lucha de la primera mitad del siglo XX entre Dios y el mono, o entre la Biblia $y$ Darwin, puede ser percibida con mucha facilidad como un combate entre superstición $y$ biología, fanatismo y ciencia, ignorancia y lucidez (Pierucci, 1992). Por eso, también es difícil, en la actualidad, encontrar el término fundamentalista como autodefinición, prefiriendo sus miembros llamarse a sí mismos evangélicos, conservadores, cristianos puros o renacidos, etc.

En definitiva, utilizar los términos integrismo o fundamentalismo para referirse a los movimientos militantes islámicos es recurrir, desde el inicio, a términos cargados de connotaciones negativas en Occidente. Pero, más allá de estas cargas negativas, también es válida la pregunta acerca de si el significado de ambos términos es correcto para designar el fenómeno del islam político.

En principio, la utilización de términos originados en el contexto cristiano no necesariamente es incompatible para el análisis de fenómenos no relacionados con el 
cristianismo. En realidad, para poder elaborar las posibles continuidades o diferencias entre todos estos fenómenos conviene emprender el examen de las bases ideológicas, los discursos y las prácticas de los movimientos islámicos, y no concentrarse en el origen geográfico o etimológico de los términos o su relación original con el cristianismo. Sin embargo, en primer lugar, se debe aclarar que fundamentalismo e integrismo no pueden ser intercambiables porque significan relaciones diferentes entre los colectivos y lo sagrado. Por lo tanto, el primer error para designar al islam político, sería la utilización indistinta de ambos términos, observable aún en bibliografía especializada.

Por ejemplo, un movimiento islámico inspirado en clérigos que reservan para sí la interpretación de las lecturas sagradas no puede ser fundamentalista porque está rechazando también el acercamiento inmediato (sin mediación del clérigo) del creyente a la Escritura, y no porque el origen del término sea cristiano.

\section{Los nombres propios}

Puesto que está claro que los términos mencionados designan otra cosa y que, en general, pero también en relación a los movimientos islámicos, la dificultad de nombrar implica la dificultad de comprender (Burgat, 1988), es que los especialistas en el Medio Oriente contemporáneo hemos buscado denominaciones propias para designar a esta movilización política basada en el discurso islámico.

Así, diversos autores recurren a diferentes nombres. Entre ellos, los más comunes son islam o islamismo radical (Carré, 1985; Étienne, 1996; Sivan, 1997), islamismo (Roy, 1996; Burgat, 1996 y 2006; Martín Muñoz, 1999; Kepel, 2001; Rashid, 2002; Arístegui, 2004; Mires, 2005; Veiga, 2011), movimientos islámicos (Brieger, 1996) o islam político (Ayubi, 1996; Brieger, 1996; Ferjani, 2009; Barreñeda, 2011; Izquierdo Brichs, 2011). Algunos autores -sobre todo vinculados a cierto islam políticamente militante- utilizan el término despertar islámico (Ramadán, 2000; Jamenei, 2013; Ahmadineyad, 2013; Rabbani, 2013; entre otros). Sin embargo, esas denominaciones encierran problemas metodológicos y conceptuales.

Bruno Étienne defiende el uso del término radical en un doble sentido. Por un lado, utiliza el radicalismo con un sentido "americano", es decir, de un islam "políticamente radical, casi revolucionario", en su cuestionamiento del orden político y económico. Por otro lado, sostiene que proponen la solución

atacando la raíz del mal. En ese sentido son radicales (...) hay que destruir el mundo para que llegue el reino (logrando el) retorno a las raíces del islam político: la ciudad ideal de los rashidun, de los cuatro califas 'bien inspirados' (Étienne, 1996, pp. 14-16). 
Sin embargo, la idea de radicalidad en el islam podría implicar también que sus adherentes son radicalmente musulmanes, esto es que se podría ser un poco menos musulmán, o serlo con menos celo. Entonces se haría coincidir el fenómeno con la mayor fidelidad a los preceptos religiosos, lo cual es un error, sobre todo porque no representa al fenómeno descripto. Cualquier musulmán podría considerar que es completamente musulmán o dicho de otro modo, que cumple con todo lo que su religión le ordena, según su interpretación, sin por eso ser un militante islamista.

Algo similar podría ocurrir con el pretendido despertar que señala, por contraste, un islam aletargado que no sería, por lo tanto, el deseable para el verdadero creyente. Esto es afirmado explícitamente por el ex presidente iraní Mahmud Ahmadineyad (2013), quien sostiene que el despertar islámico representa el regreso al "verdadero islam" y que las divergencias en el interior de la comunidad musulmana se deben a que "los musulmanes no han comprendido correctamente la esencia de su religión". Por otra parte, para el Líder Supremo iraní, Alí Jamenei (2013), ese despertar es resultado de la propia Revolución Islámica de 1979 llevada adelante por su predecesor, el Imam Jomeini.

Al igual que en el caso anterior, esta definición dejaría a la mayoría de los musulmanes practicando un islam dormido, con las concomitantes connotaciones de islam correcto/incorrecto.

En cuanto al término islamismo, su uso pretende diferenciarse del sustantivo islam, que se restringiría a la práctica religiosa, siendo el primero el que designaría su utilización política. Sin embargo, justamente, el riesgo de su uso es la confusión que puede darse entre ambos términos:

En cualquier diccionario francés anterior a 1960 podemos encontrar que 'islamismo' es sinónimo de islam; ahora se lo utiliza con un sentido político, como la voluntad de hacer de la religión musulmana una guía política (...). En Francia antes no se utilizaba la denominación 'islamismo', que lleva a confusiones horribles; yo advertí contra el uso de esa palabra, pero Gilles Kepel fue quien más hizo por difundir el término, que me parece incorrecto (Rodinson, 1996).

Por otra parte, los miembros de estos movimientos pueden contribuir a tal confusión, justamente porque para ellos practican la única manera válida de ser musulmán y los términos deberían ser intercambiables. En otras palabras, se trataría de buenos o malos musulmanes, siendo los islamistas, los primeros.

Un ejemplo de la confusión entre los términos, y del uso de los mismos en el interior de una comunidad musulmana, se dio en la crónica realizada por un periódico boliviano de una conferencia de prensa del presidente del Consejo de Ética de la Unión Nacional de Entidades Islámicas de Brasil. Ante el arresto en ese país de una supuesta célula terrorista simpatizante con el Estado Islámico, antes de los Juegos Olímpicos de Río, y denunciando la "islamofobia", el presidente del Consejo de Ética de la UNI (Unión de Entidades 
Islámicas), Jihad Hammadeh, denunció la "falta de respeto y la violencia" contra los seguidores del islamismo ${ }^{1}$ (destacado propio). Si bien el portugués permite la ambigüedad entre los términos islã e islamismo los medios brasileños transcribieron las expresiones del sheij como una condena a la "discriminação contra muçulmanos no Brasil" (destacado nuestro). La ambigüedad queda manifiesta cuando Hammadeh afirma que, a pesar de los prejuicios y la islamofobia, de ser ciertos los vínculos entre los arrestados y el terrorismo, la policía hizo un bien a la sociedad y al "próprio islamismo" (destacado nuestro).

Por su parte, Bruno Étienne (1996) rechaza el uso de islam político porque el término político, tal como lo entendemos en Occidente desde los griegos en adelante, no existe en el Corán:

Pero separar estrictamente religión y política para evitar cualquier conflicto entre ellas es una idea totalmente extraña al islam, que no sería capaz de admitir la domesticación de la religión (aquí entendida como una reducción a la esfera de lo privado). (...) La crítica del papel social de la religión no se ha desarrollado más que en Occidente y conduce a su desaparición.

Sin embargo, el término radicalismo que este autor propone puede ser mal interpretado, porque otros autores lo utilizan con connotaciones claramente negativas, como sinónimos de violencia, en contraposición a un islam moderado (Lampridi-Kemou, 2011, pp. 113-114), o como regresión o medievalización del discurso. Es el caso de Alonso Marcos, al caracterizar al Hizb ut Tahrir del Líbano, afirmando que un líder contemporáneo (an Nabhani) es más radical que uno del siglo XI (An Nasafi), quien aceptaba un gobierno no musulmán:

La distancia que separa a Umar an- Nasafi de an-Nabhani (más de ocho siglos) nos hace tener una sensación agridulce para con el mundo musulmán, pues aunque nos demuestra que el islam no es monolítico y surgen interpretaciones de lo más variadas, se percibe una tendencia hacia la radicalización en algunos sectores (Alonso Marcos, 2011).

Insistimos en el límite de la denominación de islam radical, a su vez, por otros motivos. En primer lugar, porque es posible una práctica política sustentada en el lenguaje y los valores del islam, pero altamente conservadora, quietista y, por lo tanto, nada revolucionaria. De hecho, Étienne incluye, en su estudio del islamismo radical, al islam de Arabia Saudí, que difícilmente pueda ser considerado revolucionario. En segundo lugar, porque en la actualidad ya no nos parece pertinente la salvedad que varios especialistas

\footnotetext{
1 "Los islamistas de Brasil denuncian discriminación", Correo del Sur, 23 de julio de 2016, Sucre, Bolivia, https://correodelsur.com/mundo/20160723_los-islamistas-de-brasil-denunciandiscriminacion.html, consultado el 24 de julio de 2016

2 "Entidades islâmicas no Brasil apoiam PF se houver 'provas e transparência", en http://g1.globo.com/saopaulo/noticia/2016/07/entidades-islamicas-no-brasil-apoiam-pf-se-houver-provas-etransparencia.html, consultado 26 de julio de 2016
} 
hacen al señalar que el islam no reconoce una esfera secular. Si bien es una proposición ampliamente mantenida en círculos tanto musulmanes como seculares, algunos autores la califican de mito orientalista/fundamentalista. Lo que sucedería, en realidad, es la intención islamista de "invertir la relación tradicional entre las dos esferas para que la política se convierta en subordinada a la religión, y no en el otro sentido, como fue el caso históricamente" (Ayubi, 1996).

Creemos que tal situación (de no separación entre esferas religiosa y política) no debería atribuirse al islam, sino a las dinámicas históricas entre las que se desarrolló esta religión.

En otras palabras, tampoco el judaísmo o el catolicismo aceptaban una esfera política secular, diferenciada de la religión. Pero su desarrollo histórico en Occidente generó esa división de esferas, frente a la cual debieron adaptar su discurso, sus prácticas y sus definiciones. Por ejemplo, las comunidades musulmanas desarrolladas en el mundo occidental -surgidas en las distintas corrientes migratorias en sentido este-oeste desde finales del siglo XIX y hasta la década del setenta del siglo XX-pudieron ser fieles tanto a su religión como a las leyes y constituciones, incluso laicas, de los países en los cuales residían. Esto puede dar cuenta de la posibilidad de separar las esferas religiosa y política. La diferencia, en todo caso, entre la modernidad occidental y el mundo islámico no occidental no estriba en la religión mayoritaria, sino en la ausencia, fuera de Occidente, de un proceso histórico secularizador comparable.

De hecho, el mismo Étienne afirma en otra obra (2005) que sí es posible la separación, en el islam, de lo político y lo religioso:

La separación es posible; desde el inicio del islam se plantea el problema. El califa y el imam garantizan las dos funciones de lo temporal y lo político; domina tan pronto una como la otra. (...) Hay que dejar de repetir machaconamente la media verdad de que el islam no separa lo espiritual de lo temporal, lo político de lo religioso y la esfera privada de la esfera pública. Esa afirmación no se corresponde con la realidad social y política de la mayoría de los países árabes, con la notoria excepción de Arabia Saudí (destacado propio).

También Burgat (1996) afirma que "la cultura musulmana no es nada reacia a la distinción entre los registros profano y religioso de la vida social”.

Incluso algunos autores citan un hadiz y un versículo coránico para señalar la distinción de lo político y lo espiritual en el islam:

"Lo referido a los asuntos de vuestra religión, me atañe, y lo que tiene que ver con los asuntos de vuestro mundo, vosotros sois los mejores para saberlo".

"Obedecer a Dios, obedeced al Enviado y a aquellos de vosotros que tengan la autoridad" (Ferjani, 2009). 
Si bien la definición ha sido pensada en el contexto de la modernidad occidental, podemos definir el proceso de secularización como la "adaptación a los cambios que imponen la construcción del Estado, la expansión capitalista, la desregulación y pluralización del campo religioso, la emergencia de clases y de nuevos actores sociales" (Di Stéfano, 2010, p.12).

Es decir que la secularización no implica la desaparición de la religión, sino su adecuación. Esa adecuación efectivamente se ha producido, al ser el fenómeno en cuestión propio de la modernidad del mundo árabe-islámico, pero con características tan disímiles respecto de Occidente, que resultan en un fenómeno completamente diferente.

Para la definición constituye una dificultad, sin embargo, que estas organizaciones no representen una ideología homogénea. Por el contrario, el término islamismo puede incluir a un "conjunto de proyectos ideológicos de carácter político cuyo paradigma de reivindicación es islámico", conjunto múltiple, pero que tiene "en común la reivindicación de la sharía como eje jurídico del sistema estatal y la independencia del discurso religioso de sus detentadores tradicionales", y que pueden tener un proyecto tanto pluralista y democrático como autoritario o excluyente. Otros autores lo definen como "una forma de instrumentalización del islam, por individuos, grupos y organizaciones que persiguen objetivos políticos" y que "proporciona respuestas políticas a los desafíos de la sociedad actual imaginando un futuro cuyas bases se apoyan en la reapropiación y reinvención de conceptos tomados de la tradición islámica" (Izquierdo Brichs, 2011). Para Rodinson es una "aspiración a resolver por medio de la religión todos los problemas sociales y políticos, y simultáneamente restaurar la totalidad de los dogmas" (Étienne, 1996, p. 162; Balta, 1995, p. 150). Para el islamista tunecino Rashid Gannouchi se trata de la "acción para renovar la comprensión del islam, que comenzó en los setenta y clama el retorno a sus fuentes, alejado de los mitos heredados y las tradiciones inamovibles" (Brieger, 1996, p. 15). Gema Martín Muñoz lo define optando "por el término 'islamismo' para definir al islam radical político cuyo objetivo es acceder al poder, frente al islam oficial que actúa como grupo de presión sobre el poder o colabora con él, pero no compite abiertamente por él" (destacado propio) (Martín Muñoz, 1992, p. 332).

Asimismo, existe un fenómeno diferente, propuesto, por ejemplo, por quienes sostienen que el islam político está declinando (Kepel, 2001) tanto como por quienes afirman su fracaso (Roy, 1992). Se trata de lo que estos autores denominan postislamismo o neo-fundamentalismo. En ambos casos se refieren a manifestaciones que reivindican un lenguaje islámico pero que han renunciado al proyecto político. Justamente por esa razón, debido a que el nuevo lenguaje islámico se ha convertido en una experiencia o bien interior, esotérica, o bien restringida a un ámbito colectivo, pero privado, de pequeñas comunidades, que no pretende influir en el espacio político, es decir, público, 
proponemos dejar a estas experiencias neo-comunitarias fuera de estudio del islam político.

\section{Conclusiones}

1. En cuanto a la correcta denominación, y al explicitar las salvedades anteriores, se sugiere recurrir a los términos movimientos islámicos o islam político a fin de representar a las organizaciones políticas que utilizan el islam como discurso para movilizar a sus simpatizantes y legitimar sus acciones, tanto conservadoras como revolucionarias, violentas y belicistas o pacíficas y quietistas.

a. Estas designaciones evitan tanto adjetivos que puedan remitir a la intensidad o profundidad de la identidad islámica (como radical, aletargado, renacido, etc.), y enfatizan el carácter político del fenómeno, es decir, su manifiesta intencionalidad de generar impacto, tanto conservador como contestatario, pacífico o violento, legal o revolucionario, en el ámbito público.

b. La utilización de estos términos restringiría asimismo tanto la confusión con el islam en tanto religión (evitando la utilización de islamismo), como el uso de términos inadecuados por su inexactitud para designar el fenómeno (integrismo, fundamentalismo), más que por su origen histórico occidental.

2. En relación a los enfoques que pretenden explicar el fenómeno, creemos que los tres mencionados (el cultural / religioso, el materialista / de clase y el político) son pertinentes a condición de explicitar sus límites y contradicciones:

a. En cuanto a las explicaciones culturales, su mayor riesgo es la aceptación de posiciones esencialistas, considerando a determinada cultura (en este caso la islámica) homogénea e inmutable. Es de destacar que esos caracteres inmutables o esenciales pueden considerarse tanto altamente conservadores como rebeldes. En cualquier caso, el sobredimensionamiento de estos factores culturales puede conducir a una suerte de neo-racismo, que identifique la cultura islámica como un colectivo cuyos individuos no puedan sustraerse de determinados comportamientos homogéneos y predeterminados. Sin embargo, el abordaje cultural brinda un aporte que no puede soslayarse: la interpretación del islam político como una suerte de lenguaje autóctono, propio, símbolo de un colectivo inclusivo y aglutinador, que permite a sus integrantes una participación política activa y militante, que a su vez puede expresar reivindicaciones que exceden los ámbitos de la "cultura" o la "religión": inclusión social o económica, reconocimiento simbólico, participación ciudadana, etc. 
b. Respecto a las interpretaciones políticas, los riesgos más importantes son las relaciones mecánicas que se pueden establecer entre las manifestaciones de este colectivo y las reivindicaciones de democracia o las posturas antiimperialistas, no siempre presentes en los proyectos contestatarios de los movimientos islámicos. Sin embargo, el énfasis en los elementos políticos permite focalizar la atención tanto en las situaciones particulares (evadiendo así las perspectivas esencialistas que consideren al islam como un todo homogéneo), como en las tensiones internas de las sociedades involucradas (evitando antinomias, también generalizadoras y esencialistas, como Occidente - islam). Por el contrario, los abordajes políticos nos permiten analizar las situaciones dinámicas de las sociedades estudiadas, así como el pragmatismo propio de los movimientos políticos que pretenden generar impacto (movilización, conciencia, cooptación, etc.) en la esfera pública.

c. Por último, los abordajes que enfatizan las cuestiones materiales o de clase también se enfrentan a los riesgos de establecer relaciones mecánicas entre religión y pobreza, o entre rebelión y reivindicaciones materiales, que muchas veces son desmentidas en los análisis de las situaciones particulares. Sin embargo, una vez más, el estudio de esas condiciones materiales o de intereses de clase permite analizar las situaciones particulares y las tensiones internas de las sociedades involucradas, historizando el fenómeno y alejándolo, nuevamente, de miradas esencialistas, prejuiciosas y estáticas.

\section{Referencias Bibliográficas}

Abu Amr, Z. (1994). Islamic Fundamentalism in the West Bank and Gaza. Bloomington: Indiana University Press.

Abu Amr, Z. (1996). Entrevista. En Brieger, P. ¿Guerra Santa o lucha política? Entrevistas y debates sobre el islam. Buenos Aires: Biblos.

Ahmadineyad, M. (2013). El despertar del islam es el regreso al verdadero islam. Recuperado (29/10/2013). URL: http.//hispantv.com/NewsPrint.aspx?id=223011

Alonso Marcos, A. (2011). Hizb ut Tahrir en el Líbano. Sus aportaciones al islam político. Revista CIDOB d'Afers Internacionals, 93-94, 201-217.

Al-Sayyad, N. y Castells, M. (Ed.) (2003). ¿Europa musulmana o euro-islam? Política, cultura y ciudadanía en la era de la globalización. Madrid: Alianza

Álvarez Ossorio Alvariño, I. (Ed.) (2013). Sociedad civil y contestación en Oriente Medio y norte de África, Barcelona: CIDOB.

Armstrong, K. (2004). Los orígenes del fundamentalismo en el judaísmo, el cristianismo y el islam. La intolerancia religiosa frente al progreso. Barcelona: Tusquets

Arístegui, G. de (2004). El islamismo contra el islam. Las claves para entender el 
terrorismo yihadista. Barcelona: Ediciones B.

Ayubi, N. (1996). El islam político. Teorías, tradición y rupturas. Bellaterra, Biblioteca del Islam Contemporáneo, 3.

Balta, P. (1995). L'Islam. 1500 ans d'histoire.Les schismes. L'Islam et I'islamisme. Tradition et modernité. Paris: Marabout.

Barreñeda Bajo, I. (2011). El islam político en la minoría palestina en Israel. El debate sobre la integración institucional limitada. Revista CIDOB d'Afers Internacionals, 93-94, 179-200.

Briones, C. (1998). La alteridad del "Cuarto Mundo". Una deconstrucción antropológica de la diferencia. Buenos Aires: Del Sol.

Brieger, P. (1996). ¿Guerra santa o lucha política? Entrevistas y debate sobre el islam. Buenos Aires: Biblos.

Brieger, P. y Herszkowich, E. (2003). De La Meca a las pampas. La comunidad islámica en la Argentina. Revista Todo es Historia, 430, 6-15.

Burgat, F. (1988). De la Dificulté de nommer, Intégrisme, Fondamentalisme, Islamisme. Les temps Modernes; 500, 477- 496.

Burgat, F. (1996). El islamismo cara a cara. Barcelona: Bellaterra.

Burgat, F. (2006). El islamismo en tiempos de al-Qaida. Barcelona: Bellaterra.

Campanini, M. (2003). Islam y política. Madrid: Biblioteca Nueva.

Carré, O. (1985). Radicalismes Islamiques. París: L'Harmattan.

Conde, G. (2012). Los movimientos populares árabes de 2011 y su significado histórico. En Mesa Delmonte (coord.) El pueblo quiere que el régimen caiga. Protestas sociales y conflictos en África del norte y en Medio Oriente. México: El Colegio de México.

Di Stéfano. R. (2010). Ovejas negras. Historia de los anticlericales argentinos. Buenos Aires: Sudamericana.

Elorza, A. (2002). Umma. El integrismo en el islam. Madrid: Alianza.

Étienne, B. (1996). El islamismo radical. Madrid: Siglo Veintiuno.

Étienne, B. (2005). ¿Qué inquieta del islam? Barcelona: Bellaterra.

Fadlala, H. (1995). Islamic Unity and Political Change, Journal of Palestine Studies, V. XXV, no 1, pp.61-75

Feliú, L. (2013). Islam político en Libia. Elitización y vanguardia. En Izquierdo Brichs, F. (Ed.) (2013). El islam político en el Mediterráneo. Radiografía de una evolución. Barcelona: CIDOB (pp. 233 a 267).

Ferjani, M. C. (2009). Política y religión en el campo islámico. Barcelona: Bellaterra.

Gannouchi, R. (1996). Entrevista. En Brieger, P. ¿Guerra Santa o lucha política? Entrevistas y debates sobre el islam (pp. 59 a 74). Buenos Aires: Biblos.

Garaudy, R. (2001). Los integrismos. El fundamentalismo en el mundo. Barcelona: Gedisa. 
Gellner, E. (1991). Naciones y nacionalismo. Buenos Aires: Alianza.

Goody, J. (2005). El islam en Europa. Barcelona: Gedisa.

Grimson, A. y Semán, P. (2005). Presentación. La cuestión 'cultura'. Etnografías Contemporáneas, 1.

Gutiérrez de Terán, I. y Álvarez Ossorio, I. (2012). Informe sobre las revueltas árabes. Madrid: Ediciones del Oriente y del Mediterráneo.

Herszkowich, E. (2006). El islam político entre el cielo y la tierra. Sextas jornadas de Medio Oriente. Después de Irak. Los Nuevos desafíos en Medio Oriente, Instituto de Relaciones Internacionales, Universidad Nacional de La Plata, 22 de noviembre 2006.

Hobsbawm, E. (1992). Naciones y nacionalismo desde 1780. Barcelona: Crítica.

Huntington, S. (1997). El choque de civilizaciones. Buenos Aires: Paidós.

Izquierdo Brichs, F. (2011). Islam político en el siglo XXI. Revista CIDOB d'Afers Internacionals, 93-94, 11-32.

Izquierdo Brichs, F. (Ed.) (2012). El islam político en el Mediterráneo. Radiografía de una evolución. Barcelona: CIDOB.

Jamenei, A. (2013). El despertar Islámico continúa. Recuperado (29/10/2013). URL: http.//www.webislam.com/noticias/91377-ayatullah_jamenei_el_despertar_ islamico_continua.html

Jameson, F. y Zizek, S. (2003). Estudios culturales. Reflexiones sobre el multiculturalismo. Buenos Aires: Paidós.

Josrokhavar, F. y Roy, O. (2000). Irán de la revolución a la reforma. Barcelona: Bellaterra.

Kepel, G.(2001). La Yihad, expansión y declive del islamismo. Barcelona: Península.

Lampridi-Kemou, A. (2011). Los Hermanos Musulmanes. ¿Una fuerza centrífuga o centrípeta?. Revista CIDOB d'Afers Internacionals, 93-94, 111-127.

Laroui, A. (1991). La crisis de los intelectuales árabes. Madrid: Libertarias.

Lewis, B. (2003). La crisis del islam. Guerra santa y terrorismo. Barcelona: Ediciones B.

Löwy, M. (1996). Entrevista. En Brieger, P. ¿Guerra Santa o lucha política? Entrevistas y debates sobre el islam (pp. 167 a 183). Buenos Aires: Biblos.

Martín Muñoz, G. (1992). Política y elecciones en el Egipto contemporáneo (19221990). Madrid: Instituto de Cooperación con el Mundo Árabe.

Martín Muñoz, G. (1999). El Estado Árabe. Crisis de legitimidad y contestación islamista. Barcelona: Bellaterra.

Mires, F. (2005). El islamismo. La última guerra mundial. Buenos Aires: Libros de la Araucaria. 
Piñeiro Carreras, J. (2004). Islam, religiosidad e identidad. Posibilidades y límites de la comparación entre un caso argentino y uno brasileño. Simposio Internacional Fronteiras na América Latina, UPSM, Brasil.

Pierucci, A. F. (1992). Fundamentalismo e integrismo. os nomes e a coisa. Revista USP, $\quad 13, \quad$ 144-156. Recuperado 28/12/2013. URL: http.//www.revistas.usp.br/revusp/article/view/25620

Rabbani, Z. El despertar islámico. Recuperado 29/10/2013. URL: http.//www.asai.org.ar/index.php/otros-temas-articulos/134-el-despertarislamico.html

Ramadán, T. (2000). El reformismo musulmán. Desde sus orígenes hasta los Hermanos Musulmanes. Barcelona: Bellaterra.

Ramadán, T. (2002). El islam minoritario. Cómo ser musulmán en la Europa Laica. Barcelona: Bellaterra.

Rashid, A. (2002). Yihad. El auge del islamismo en Asia Central. Barcelona: Península.

Rodinson, M. (1996). Entrevista. En Brieger, P. ¿Guerra Santa o lucha política? Entrevistas y debates sobre el islam (pp. 119 a 134). Buenos Aires: Biblos.

Roy, O. (1996). Genealogía del islamismo. Barcelona: Bellaterra.

Roy, O. (2003). El Islam mundializado. Los musulmanes en la era de la globalización, T. 20. Barcelona: Bellaterra.

Roy, O. (2006). El islam en Europa. ¿Una religión más o una cultura diferente?. Madrid: Editorial Complutense.

Sartori, G. (2001). La sociedad multiétnica. Puralismo, multiculturalismo y extranjeros. Taurus: Madrid.

Serfaty, A. (1996). Entrevista. En Brieger, P. ¿Guerra Santa o lucha política? Entrevistas y debates sobre el islam (pp. 185 a 200). Buenos Aires: Biblos.

Sivan, E. (1997). El islam radical. Teología medieval, política moderna. Barcelona: Bellaterra.

Sorj, B. (2007). Diáspora, judaísmo y teoría social. Revista Cultura y Religión, 1, (1). URL:

http.//www.revistaculturayreligion.cl/index.php/culturayreligion/article/view/207/196

Ternisien, X. (2007). Los Hermanos Musulmanes. Barcelona: Bellaterra.

Vagni, J. J. (2011). Levantamientos en el mundo árabe. Posicionamientos y lecturas desde Sudamérica, Documento de trabajo $n^{\circ} 84$, XXIII SIMPOSIO ELECTRÓNICO INTERNACIONAL MEDIO ORIENTE $Y$ NORTE DE ÁFRICA ESTADOS ALTERADOS Y LA GEOPOLÍTICA DE LA TRANSFORMACIÓN, 7 de noviembre al 2 de diciembre de 2011. 
Veiga, F. (2011). Neoliberalismo, tecnocracia e islamismo nacional. El Movimiento Gülen. Revista CIDOB d'Afers Internacionals, 93-94, 219-237. 